\title{
Article
}

\section{Emotional self-efficacy, conduct problems, and academic attainment: Developmental cascade effects in early adolescence}

Wigglesworth, M, Qualter, Pamela and Humphrey, N

Available at http://clok.uclan.ac.uk/14911/

Wigglesworth, M, Qualter, Pamela and Humphrey, N (2017) Emotional selfefficacy, conduct problems, and academic attainment: Developmental cascade effects in early adolescence. The European Journal of Developmental Psychology, 14 (2). pp. 172-189. ISSN 1740-5629

It is advisable to refer to the publisher's version if you intend to cite from the work. http://dx.doi.org/10.1080/17405629.2016.1180971

For more information about UCLan's research in this area go to http://www.uclan.ac.uk/researchgroups/ and search for <name of research Group>.

For information about Research generally at UCLan please go to http://www.uclan.ac.uk/research/

All outputs in CLoK are protected by Intellectual Property Rights law, including Copyright law. Copyright, IPR and Moral Rights for the works on this site are retained by the individual authors and/or other copyright owners. Terms and conditions for use of this material are defined in the policies page.

\section{CLoK}

Central Lancashire online Knowledge www.clok.uclan.ac.uk

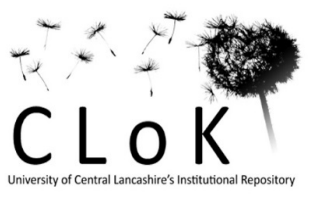


2 Emotional self-efficacy, conduct problems, and academic attainment:

3 Developmental cascade effects in early adolescence

4

5 Michael Wigelsworth ${ }^{1}$, Pamela Qualter $^{2}, \&$ Neil Humphrey ${ }^{1}$

6 1. Manchester Institute of Education, University of Manchester,

7 Manchester, UK

8 2. School of Psychology, University of Central Lancashire, Preston, UK

9

10 Other: M.,Wigelsworth, P., Qualter, and N., Humphrey (2016): Emotional

11 self-efficacy, conduct problems, and academic attainment: Developmental

12 cascade effects in early adolescence. European Journal of Developmental

13 Psychology, DOI: 10.1080/17405629.2016.1180971

14

15 It is advisable to refer to the publisher's version if you intend to cite from the

16 work. To link to this article, please go to the following URL:

17 http://dx.doi.org/10.1080/17405629.2016.1180971

18

19 
22 The study is amongst the first of its kind to utilise developmental cascade

23 modelling in order to examine the inter-relations between emotional self24 efficacy, conduct problems, and attainment in a large, nationally 25 representative sample of English adolescents ( $n=2,414$, aged 11 years). 26 Using a 3-wave, longitudinal, cross lagged-design, we tested three cascading 27 hypotheses: adjustment erosion, adjustment fortification, and academic 28 incompetence. A fourth hypothesis considered the role of shared risk. 29 Results supported small effects consistent with the cascade hypotheses, and 30 a small but significant effect was found for shared risk. Strengths and limits of 31 the study are considered alongside a discussion of the implications for these 32 findings.

37 Keywords: emotional self-efficacy; conduct problems; attainment; 38 developmental cascade 


\section{Introduction}

Developmental cascades are, "the cumulative consequences for

42 development of the many interactions and transactions occurring in

43 developing systems that result in spreading effects across different levels, 44 among domains at the same level, and across different systems or 45 generations" (Masten \& Cicchetti, 2010, p.491). Drawing on ecological and 46 developmental systems theories (e.g. Bronfenbrenner, 2005; Lerner \& 47 Castellino, 2002), the body of work in this area predicts that functioning in 48 different domains, levels, or systems are developmentally related. Namely, 49 successful accomplishment of developmental tasks in a given domain 50 provides a scaffold for later functioning in the same and other domains; 51 equally, failures in these tasks can trigger negative cascade effects. In this 52 paper we use a developmental cascade model to examine longitudinal inter53 relationships between emotional self-efficacy, behaviour problems, and 54 academic attainment in early adolescence. The model is used to test three 55 key hypotheses in the study of developmental cascades - adjustment erosion, 56 academic competence, and shared risk (Moilanen, Shaw, \& Maxwell, 2010) 57 and a fourth prediction drawing on the positive youth development perspective 58 (Lewin-Bizan, Bowers, \& Lerner, 2010), which we term 'adjustment 59 fortification'.

60 
Our focus on adolescence is driven by the fact that this period is

64 marked by major physical, psychological, behavioural, and contextual 65 changes, including the onset of puberty, the transition to secondary school, 66 and substantial neurological reorganisation (Coleman, 2011). Adolescence is 67 a captivating, critical life stage that has important repercussions for later life 68 (Hagell, Coleman \& Brooks, 2013). This is particularly true of the domains of 69 functioning that we examine in the current study. For example, we know that 70 up to $50 \%$ of adult mental health problems have their first onset in 71 adolescence (Belfer, 2008). Similarly, academic competence in adolescence 72 predicts future academic success and transition to the workplace (Ek, Sovio, 73 Remes \& Jarvelin, 2005). What is less known currently is the nature of interrelationships between these domains during this important period. We also know relatively little about the potential role played by adolescents' emotional self-efficacy in interrupting symptom-driven pathways and promoting positive adjustment. 8

Extant research on developmental cascades typically tests one or more of three key hypotheses. First, the adjustment erosion model predicts that mental health problems lead to later academic difficulties (Moilanen et al., 2010). For example, aggressive and disruptive behaviour can undermine academic progress because of its effect on relationships with school staff and peer acceptance. This is particularly salient in early adolescence because of the increased emphasis on academic ability and reduced tolerance for disruption seen in secondary education (Humphrey \& Ainscow, 2006). Research by Moilanen et al (2010) offers support for this hypothesis, with high 
88 levels of externalising difficulties in middle childhood predicting low academic competence in early adolescence. Second, the academic incompetence model suggests that difficulties relating to academic competence can trigger

91 or exacerbate mental health problems (Moilanen et al., 2010). Youth who are 92 less academically able may experience considerable frustration and 93 disaffection that eventually manifests as aggressive and disruptive behaviour. 94 As above, this is a particularly critical consideration in adolescence given the increasingly high stakes nature of academic assessments in secondary education. By way of illustration, Vaillancourt, Brittain, McDougall, and Duku's (2013) recent study evidenced clear cascade effects of low academic grade point average on later externalising behaviour problems in the late childhoodearly adolescence period. Finally, the shared risk model stipulates that cascade effects such as those outlined above are a function of other variables that affect multiple domains of development more generally. For instance, economic disadvantage (often categorised in education research as eligibility for free school meals (Gorard, 2012)) is a well-known risk factor for lower academic attainment (Department for Education, 2015) and higher socialemotional difficulties (Bradley \& Corwyn, 2002). This has been attributed to a number of factors including a lack of ease or unwillingness to access resources and associated parental beliefs and behaviours around education (Davis-Kean, 2005). Also, research consistently demonstrates that being identified as having special educational needs (an expanse term in education, denoting particular needs or disabilities beyond a school's resource capabilities) puts a child at risk of experiencing significantly worse academic and psychosocial outcomes through the course of schooling (e.g. Department 
113 for Education, 2013, Van Cleave \& Davis, 2006). This is attributable to a

114 number of causes, including an over-representation as victims of bullying

115 (Monchy et al., 2004; Van Cleave \& Davis, 2006) and poor social relationships

116 (Frostad \& Pijl, 2007, Pijl et al., 2008; Valäs, 1999). These outcomes are, of

117 course, deeply inter-related (Frederickson \& Furnham, 2004; Kaukiainen et al.,

118 2002). However, these factors have not been fully explored within a

119 developmental cascades framework. Deighton et al.'s (under review) recent

120 study provides some confirmatory evidence, demonstrating that pathways

121 from academic attainment to later internalising and externalising problems

122 were rendered insignificant once socio-economic and disability status was

123 taken into account in their late childhood sample, warranting further 124 investigation.

126 The aim of the current study was to extend understanding of 127 developmental cascade processes by addressing several gaps, limitations, 128 and inconsistencies in the existing evidence base. First, sample sizes are 129 often modest (e.g. $n=85$ in Bornstein, Hahn, \& Suwalsky, 2013b) and drawn 130 from highly specified populations (e.g. McCarty et al.'s (2008) study of 131 adolescent girls from low-income households). This reduces test sensitivity 132 (Masten et al., 2005) and limits generalizability and comparability of findings 133 (Deighton et al., under review). Hence, we drew upon a large, representative 134 sample of adolescents. Second, most studies in this area have been carried 135 out in North America. Transferability of findings cannot be assumed because 136 the cultural context is a primary component of the developmental eco-system. 137 For example, socialisation practices relating to emergent behaviour problems 
138 can vary across countries and cultures (Chen, Huang, Chang, Wang, \& Li,

139 2010). The current study is among the first of its kind in England. Third,

140 following Deighton et al (under review), we took the opportunity to extend

141 assessment of shared risk to include disability status, which has been

142 neglected in previous research despite its associations with both academic

143 achievement (Department for Education, 2013) and conduct problems (Green,

144 McGinnity, Meltzer, Ford, \& Goodman, 2005). Fourth, developmental

145 cascade research has traditionally focused on symptom-driven pathways, with

146 less attention paid to the potential fortifying effects of positive adjustment in

147 key developmental domains (Lewin-Bizan et al., 2010). Thus, we sought to

148 integrate a positive youth development perspective by assessing the cascade 149 pathways emanating from and to adolescent emotional self-efficacy.

150 Emotional self-efficacy as a positive adjustment marker caries considerable

151 intuitive appeal; emotion regulation and social problem-solving skills are likely

152 to influence both behaviour and learning in the school context (Qualter,

153 Gardner, Pope, Hutchinson, \& Whiteley, 2012; Qualter, Dacre-Pool, Gardner, 154 Ashley-Kot, Wise, \& Wols, 2015). Accordingly, emotional self-efficacy forms a 155 key aspect of many non-cognitive school based interventions (Durlak, 156 Weissberg, Dymicki, Taylor, \& Schellinger, 2011; Sklad, Diekstra, Ritter, \& 157 Ben, 2012; Wigelsworth et al., in press). Both its hypothetical presence and 158 empirical measurement have typically assumed a linear development (as 159 proposed above), but our understanding of this relationship is incomplete with 160 further consideration of the potential inter-relations within a cascade model. 161 For instance, to what extent do conduct problems mediate the relationship 162 between emotional self-efficacy and academic attainment across time? 
164 Finally and critically, research findings pertaining to the adjustment 165 erosion, academic incompetence and shared risk hypotheses have been 166 inconsistent. For example, in contrast to the findings of Moilanen et al. (2010) 167 outlined above, Romano, Babchishin, Pagani, and Kohen (2010) found no 168 significant links between behaviour problems and later attainment. Thus, the 169 current study confers an opportunity to provide further clarification of the 170 nature and magnitude of developmental cascade effects.

\section{Aims and objectives}

The primary aim of the current study was to examine the longitudinal interrelationships between emotional self-efficacy, behaviour problems and

176 academic attainment in early adolescence. To achieve this aim, we sought to 177 test four hypotheses, as follows:

1. Adjustment erosion - early behaviour problems will lead to later academic difficulties $(\mathrm{H} 1 \mathrm{a})$ and lower emotional self-efficacy $(\mathrm{H} 1 \mathrm{~b})$.

2. Adjustment fortification - early emotional self-efficacy will lead to enhanced academic attainment $(\mathrm{H} 2 \mathrm{a})$ and reduced behaviour problems (H2b).

3. Academic incompetence - early academic difficulties will lead to later behaviour problems $(\mathrm{H} 3 \mathrm{a})$ and lower emotional self-efficacy $(\mathrm{H} 3 \mathrm{~b})$. 
4. Shared risk - cascading effects in H1-3 above are attributable to common cause risk markers, specifically socio-economic and disability status.

In each of the above hypotheses, we examine cross-time cascading effects, whilst controlling for cross-time, within-domain stability, and withintime, cross-domain co-variance (see ‘analytical strategy').

\section{Method}

The study utilizes secondary analysis of data from a governmentfunded evaluation of a universal social-emotional learning intervention in English secondary schools (Humphrey, Lendrum, \& Wigelsworth, 2010). Here we make use of a longitudinal, cross-lagged panel design with 3 annual waves of measurement - T1, T2 and T3 (T1 and T3 only for academic attainment - see below).

\section{Participants}

The final sample was made up single cohort of 2,414 children. All children were in their first year of secondary education (year 7 , aged 11 years) at T1, drawn from 41 geographically diverse secondary schools in England. One sample $t$-tests confirmed that the study sample mirrored national norms in terms of attainment, attendance, proportion of children eligible for free school meals (FSM) (as a proxy for socio-economic status) and proportion of 
211 children with special educational needs (SEN) (as a proxy for disability status)

212 at the school level, and sex, ethnicity, FSM eligibility and SEN status at the

213 child level. Study schools were shown to be slightly larger than is seen

214 nationally.

215

216

Approximately $53.5 \%(N=1291)$ of the study sample were female,

$21782.6 \% \quad(N=1994)$ were classified as 'White British', 9.9\% (N=239) were

218 identified as eligible for FSM, and 12.9\% $(N=312)$ were identified with SEN.

\section{Measures}

Conduct problems

Conduct problems (CP) were assessed using the relevant subscale in

225 the self-report version of the Strengths and Difficulties Questionnaire (SDQ)

226 (Goodman, 1997). This 25-item (5 items in the CP subscale) behavioural

227 screening measure requires respondents to endorse a series of descriptive

228 statements (e.g. 'I get very angry and lose my temper') on a three-point scale

$229(0=$ not true, $1=$ somewhat true, and $2=$ certainly true $)$. The SDQ has robust

230 psychometric characteristics (Goodman, 2001) and is amongst the most

231 widely used measures of its kind (Johnston \& Gowers, 2005). In the current

232 sample, $\alpha$ ranged between $.611-.633$ across each year the subscale was

233 used. This is approximately consistent to a reported alpha value of .60 for the

234 conduct problems subscale in a community sample of 5-15 year olds

235 (Goodman, 2001). 
240 Literacy Assessment and Intervention (ELAI) instrument (Southampton

241 Psychology Service, 2003). This is a 25-item self-report survey that assesses

242 emotion-related dispositions and self-perceptions, producing a single,

243 broadband indicator. Traditionally this has been branded 'trait emotional 244 intelligence' but ESE is an increasingly used synonym (Petrides, Furnham, \& 245 Mavroveli, 2007). Respondents endorse descriptive statements (e.g., 'I am 246 aware of my own strengths and weaknesses') using a 25-point scale. The 247 ELAI has acceptable psychometric properties (Southampton Psychology 248 Service, 2003). $\alpha$ ranged between .752-.762 across each year the scale was 249 used.

251 Academic attainment

253 Measures of academic attainment were extracted from a governmental 254 database (the National Pupil Database - NPD) and represented compulsory 255 academic testing at the end of Key Stages of education ${ }^{1}$. Key Stage 256 assessments record children's attainment in the core curriculum subjects of 257 English, Math, and Science. These were aggregated in the current study. We 258 utilised children's Key Stage 2 (KS2) and Key Stage 3 (KS3) attainment 259 scores, which aligned with T1 and T3 (but use different scoring scales). No 
260 compulsory testing occurred at T2 - hence, this is absent from the panel

261 design.

Shared risk

265 Additional data extracted from the NPD provided indices of socio-economic 266 and disability status. For the former, we used the Income Deprivation 267 Affecting Children Index (IDACI). This gives the deprivation ranking of the 268 neighbourhood in which a child lives; the score represents the proportion of 269 children under 16 in that area who live in a low-income household. Scoring is 270 from 0 to 1 , with higher scores representing increased deprivation. For the 271 latter, we drew on information recorded about the nature of any special 272 educational provision made for a given child (known as Special Educational 273 Needs - SEN), and this was used to operationalise a categorical variable as 274 follows: (i) no additional provision (coded 0); (ii) School Action - reasonable 275 adjustments to normal teaching practice (coded 1); (iii) School Action Plus 276 additional support provided by an external professional (e.g., speech and 277 language therapist) (coded 2); and (iv) Statement of special educational need 278 (coded 3) - a multi-professional assessment provides the foundation of a legal 279 document outlining support needs and securing financial support for 280 appropriate provision.

\section{Procedure}


284 For each wave of data collection participating schools administered paper 285 surveys using a standardised instruction sheet. Survey completion was 286 conducted on a whole-year or whole-class basis. School staff supported any 287 students with literacy difficulties to enable them to access the measures. 288 Completed measures were collected, delivered, scored and input by 289 independent companies. The first author conducted checks on the integrity of 290 the data to ensure accuracy of scoring. Responses were tracked through 291 each wave of data collection and matched to NPD data through the use of a 292 unique reference number. This information was used solely for accurate data 293 matching and was destroyed shortly thereafter.

\section{Analytical strategy}

Tabulated pattern analysis showed that less than $1 \%$ of missing cases across 298 all three time points were attributable to any of the socio-demographic factors 299 included in the analysis, indicating no discernible pattern to missing data. 300 Therefore, incomplete cases were removed on a list wise basis and analyses 301 were conducted for all complete cases.

303 Cascade and shared risk effects were tested using manifest structural 304 equation models in MPLus version 7 (Muthen \& Muthen, 2012). Consistent 305 with previous work in this area (e.g. Moilanen et al, 2010), we first tested a 306 simple cascade model that assessed cascade pathways across domains over 307 time while accounting for temporal stability and within-time co-variance. A 308 second model was then constructed in which the shared risk variables were 
309 added as predictors of each domain at each time point. These steps are

310 diagrammed in Figure 1. In both instances, model fit was assessed using $\chi^{2}$

311 goodness of fit, Comparative Fit Indices (CFI), the Tucker-Lewis Index (TLI)

312 and Root Mean Square Error of Approximation (RMSEA) (including 90\%

313 Confidence intervals). Model fit was considered to be acceptable if CFI and

314 TLI were above .95, RMSEA was below .05 (Bollen \& Curran, 2006) and

315 SRMR was below .08 (Hu \& Bentler, 1999).

316

Results

Descriptive statistics

323 Table 1 presents descriptives and correlations for all of the study variables.

324 Skew and Kurtosis were seen to be within acceptable range \pm 1.5 (Tabachnick 325 \& Fidell, 2013), omitting a very minor violation for IDACl. Almost all variables 326 were at least moderately correlated, with the highest correlations being 327 consistent with a priori expectations (i.e., correlations of the same measure 328 between time points). 
333 All pathways in the model were tested, but in the interests of clarity, only

334 significant pathways are included in Figures 2 and 3. Given the limitations 335 associated with significance testing (Hubbard \& Lindsay, 2008), we highlight 336 pathways with a co-efficient of at least .10 in bold; this corresponds to the oft337 cited conventions for the smallest effect of interest, deemed to be, "not so 338 small as to be trivial" (Cohen, 1992, p.156). RMSEA and TLI fell below the 339 established thresholds for both models described in the analytical strategy. A 340 partial explanation is offered by the combination of relatively high size of 341 correlations in a longitudinal model over such a short time period and the 342 large sample size. This is supported by a marginal improvement in model fit 343 for the second model (see Figures $2 \& 3$ ), supporting the inclusion of IDACI 344 and SEN. However, overall fit is sub-optimal, possibly suggesting the 345 presence of exogenous variables not accounted for in the current model.

\section{${ }^{* * *}$ FIGURE 2***}

347 Figure 2 shows the developmental cascade modelled to address hypotheses

$3481 \& 2$, specifically including the cross lagged pathways across all time points 349 for emotional self-efficacy, conduct problems, and academic attainment (after 350 accounting for temporal stability and concurrent correlations). Aside from the 351 pathways controlling for stability across time, the largest effects were seen

352 between T1 conduct problems predicting T2 emotional self-efficacy, and 353 subsequent T2 emotional self-efficacy predicting T3 conduct problems. This 354 is suggestive of a cascading relationship between these constructs. 355 Regarding hypotheses 1 and 2, there is evidence to support the presence of 356 both adjustment erosion and academic incompetence. Adjustment erosion is 357 indicated by the significant pathway between T1 conduct problems and T3 
358 academic attainment, which although significant and in the direction

359 hypothesised (a rise in conduct problems is associated with a reduction in

360 academic attainment), the resulting effect is comparatively small (-.030) in

361 relation to other pathways in the model. There is arguably a slightly stronger

362 case for the presence of academic incompetence, because the relevant

363 pathway (T1 academic attainment to T3 conduct problems) is significant, in

364 the direction hypothesised (lower academic attainment is associated with a

365 rise in conduct problems), and is of relatively large effect (-.107) in relation to

366 the other pathways in the model. A similar pattern is shown between T1

367 academic attainment and T2 conduct problems, but to a lesser magnitude ($368 \quad .073)$

370 In order to test for the effect of shared risk variables on the cascade effects

371 identified in the model above, SEN and IDACI were regressed onto each

372 factor, shown in Figure 3. Results showed a significant contribution of shared 373 risk factors for the majority regressed pathways, across all time points. 374 However, given the established associations of SEN and IDACI with both 375 mental health (Green et al, 2005) and academic achievement (Department for 376 Education, 2011), further significant pathways may have been expected. For 377 instance, there is no significant pathway between SEN and T3 academic 378 attainment. Similarly, associated effect sizes are relatively small, with only T1 379 shared risk pathways surpassing Cohen's effect of .1.

380 Regarding the effects of the previously identified pathways in Figure 2, there 381 is an almost identical pattern of findings, with only minor changes to the 382 academic pathways (T1 academic attainment to $\mathrm{T} 2$ conduct problems 
383 reduced in strength, T1 academic attainment to emotional self-efficacy

384 increased in strength). This provides partial support for hypothesis 3.

\section{Discussion}

387 The current study sought to examine the development of children's conduct 388 problems, and its association with academic attainment, in order to better 389 understand the cumulative effects over time and interactions across

390 developing systems. We integrated emotional self-efficacy into the 391 developmental cascades model to examine emotional self-efficacy as a 392 process that might explain the relationship between children's conduct 393 problems and academic attainment. Disability and socio-economic status 394 were also examined as shared risk factors. We also used a large, nationally 395 representative dataset in the current study, enhancing the confidence by 396 which results can be generalised to the wider school-based population. Three 397 hypotheses were examined, consistent with developmental cascade theory, 398 especially examination of evidence for adjustment erosion, academic 399 incompetence, and shared risk. We examined adjustment fortification and 400 hypothesized that early high levels of emotional self-efficacy will lead to 401 enhanced academic attainment and reduced behaviour problems.

403 Consistent with adjustment erosion and academic incompetence models, 404 there was some evidence to suggest that developmental cascade effects 405 were in effect. Path models suggested that higher levels of conduct problems 406 at age 11 (Time 1) were associated with poorer academic competence at age 
13 (Time 3). In turn, poor academic competence at age 11 was related to

408 higher levels of conduct problems at ages 12 and 13. Higher levels of conduct

409 problems at age 11 were also linked to lower levels of emotional self-efficacy

410 at age 12, which then predicted increased conduct problems at age 13. High

411 levels of conduct problems around the time of entry to High school (age 11)

412 were predictive of lower levels of emotional self-efficacy at age 12 and lower

413 levels of academic attainment at age 13. Finally, the shared risk analyses

414 suggested that socio-economic adversity and special educational need status

415 played a small role in the link between early externalizing problems and

416 academic competence in middle childhood. The current pattern of results

417 support previous research, which showed path links from conduct (i.e.

418 externalised) problems to academic incompetence in early to middle

419 childhood (e.g. Campbell et al., 2006; Capaldi, 1992; Chen et al., 1997;

420 Moilanen, Shaw, \& Maxwell, 2010; Morgan et al., 2008). The inclusion of

421 shared risk variables did little to alter the magnitude or statistical significance

422 of any of the established pathways, suggesting that findings pertain to

423 different groups of academic attainment, including those across a socio-

424 economic spectrum and for those pupils identified with SEND. However,

425 practical limitations prevent a more detailed investigation of these groups

426 (SEND in particular), as the data were restricted to school-based provision.

427 Therefore, in future work, there is an opportunity to examine whether the

428 same patterns of effects can be found for those at the extremely high end of

429 youth externalizing problems, and those with other clinical problems. It is

430 noteworthy that all significant paths emerged after accounting for

431 autoregressive effects of each domain, which were moderately high in 
432 magnitude in all three domains of child adjustment. This is indicative of the 433 comparatively short time scale of the measurements, in comparison to

434 broader developmental cascade literature, which can span up to 20 years (e.g.

435 Masten et al., 2005).

436 There was evidence to support the adjustment fortification model, with higher 437 levels of emotional self-efficacy at T1 and T2 predicting lower levels of 438 conduct problems at T2 and T3 respectively, and higher academic attainment 439 at T3. These findings support previous work that shows poor emotional 440 competence in adolescence predicts school difficulties associated with 441 subsequent academic underachievement (e.g. school drop-out and persistent 442 antisocial behaviour) (Gagnon, Craig, Tremblay, Zhou, \& Vitaro, 1995; 443 Haapasalo \& Tremblay, 1994; Kochenderfer \& Ladd, 1996; Petrides et al., 444 2004; Qualter et al., 2012; Vidal Rodeiro, Bell, \& Emery, 2009). Our work 445 extends those findings and is the first to highlight the importance of emotional 446 self-efficacy in developmental cascades of conduct problems and academic 447 achievement.

449 Those findings are in line with Bandura's theoretical model $(1986,1999,2001)$ 450 that argues that emotional self-efficacy is likely to influence whether 451 adolescents think in an enabling way when considering social engagement 452 and academic performance. It also affects how much effort adolescents will 453 invest in a particular revision or social strategy, how they persevere in the 454 face of social and academic difficulties, and how resilient they are to social 455 and academic stressors. Our findings provide support for the idea that lower 456 perceived emotional self-efficacy predicts higher levels of externalizing 
457 problems and poor academic attainment. The finding that emotional self-

458 efficacy influences the developmental sequence between conduct problems

459 and academic attainment further supports the thesis that self-efficacies are an

460 indicator of successful development during adolescents and intervention

461 might be well suitable to the targeting of that domain.

462

463 Strengths, Limitations, and Future Study

464 A particular strength of the current study is the use of a large community 465 based sample that is representative of the general population. Also, 466 contrasting previous studies, we used national standardized test scores as 467 our measure of academic attainment at Time 1 and Time 3 . These are 468 relatively free from reporter bias when compared to concurrent adolescent 469 self-reported attainment scores (Pataley, Deighton, Fonagy, \& Wolpert, 2015). 470 Additionally, the use of standardized test scores permits the results in a 471 national context and supports future attempts at replication of our results.

473 Regarding limitations: First, the use of self-reported conduct problems by 474 young people could not be avoided in the current study. While the 'gold 475 standard' is to source multiple reporters (De Los Reyes, 2013), it was not 476 practical in this large community based longitudinal studies. Second, the 477 multi-level structure of the data (i.e. children clustered into schools) was not 478 accounted for in the analysis because the group level sample size (41) was 479 below minimal recommendations for analyses of this type (Hox \& Maas, 2001). 480 However, mental health outcomes typically feature very small inter-cluster 481 correlations (typically around .02\% (Hale et al., 2014)). Third, resultant model 
482 fit was seen to be sub optimal. Although some explanation is likely to be

483 attributable to sample size and the strength of the within-domain correlations,

484 further consideration is required. Failure to capture idiosyncratic or even 485 systemic exogenous variables may be accountable, though this is difficult to 486 substantiate in the current design. We welcome further exploration in this 487 field (both theoretical and empirical) to establish a more accurate 488 representation of the apparent cascade effects.

489 Fourth, given the established paucity of the application of developmental 490 cascade theory in the current context (i.e. psychosocial and academic 491 measures within relatively short time period), there is a difficulty in 492 establishing 'benchmark' figures for effect sizes. Available literature indicates 493 effects are likely to be small. E.g. Deighton et al. (in press) report comparable 494 effects, however as this study was also conducted over a two-year period, this 495 may also be an artefact of the stability of the within domain correlations. A 496 future direction therefore, is to consider capturing a longer time period, 497 encapsulating more of a child's educational career.

498 Despite these limitations, the current paper is an early step in demonstrating 499 the usefulness and contribution of developmental cascade theory for 500 understanding the prospective associations between conduct problems, 501 emotional self-efficacy, and academic attainment, and in establishing 502 expectations for relative effects in the field.

503 This study represents a rigorous test of cascade effects of conduct problems, 504 emotional self-efficacy, and academic attainment in early adolescence. In 505 future cascade studies, it will be important to consider the developmental 
506 timing of these effects. It is possible that there will be differences in the 507 pattern of effects based on the developmental timing of these events. For 508 example, in our sample, emotional self-efficacy contributed to how the

509 adolescents transitioned into High School, but it may become more important

510 during later stages of adolescents when adolescents will have to deal more

511 with peer pressure and also manage the conflicting desire to engage with 512 peers compared to revision. Thus, as peer relations become a more salient

513 domain of social adjustment, the association between academic attainment 514 and emotional self-efficacy is likely to become stronger. Further study is 515 needed to examine changes in the patterns over time and how those can be 516 accounted for by the changing social and academic environments.

518 Conclusion

520 The current study offers a valuable contribution to the emergent literature on 521 developmental cascades examining self-efficacy, conduct problems, and 522 academic attainment in an educational setting. Of particular note is the use of 523 a large, representative sample of English adolescents, demonstrating an 524 inclusiveness and rigour currently lacking in the field. Accordingly, new (but 525 tentative) benchmarks are provided for future research. 
Bandura, A. (1986). Social Foundation of Thought and Action. New Jersey: Prentice Hall.

Bandura, A. (1999). A social cognitive theory of personality. In L. Pervin \& O. John (Eds.), Handbook of Personality (2nd ed., pp. 154-196). New York: Guilford.

Bandura, A. (2001). Social cognitive theory: An agentic perspective. Annual Review of Psychology, 52, 1-26.

Belfer, M. L. (2008). Child and adolescent mental disorders: the magnitude of the problem across the globe. Journal of Child Psychology and Psychiatry, and Allied Disciplines, 49(3), 226-36. doi:10.1111/j.14697610.2007.01855.x

Bollen, K. A., \& Curran, P. J. (2006). Latent curve models: A structural Equation Approach. Hoboken, NJ: Wiley and Sons.

Bornstein, M. H., Hahn, C.S., \& Suwalsky, J. T. D. (2013a). Developmental pathways among adaptive functioning and externalizing and internalizing behavioral problems: Cascades from childhood into adolescence. Applied Developmental Science, 17, 76-87. doi:10.1080/10888691.2013.774875

Bornstein, M. H., Hahn, C.S., \& Suwalsky, J. T. D. (2013b). Language and internalizing and externalizing behavioral adjustment: developmental pathways from childhood to adolescence. Development and Psychopathology, 25, 857-78. doi:10.1017/S0954579413000217 
548 Bradley, R., \& Corwyn, R. (2002). Socioeconomic status and child

549 development. Annual Review of Psychology, 53, 371-399.

550 Bronfenbrenner, U. (2005). Making Human Beings Human: Bioecological 551 Perspectives on Human Development. London: Sage Publications.

552 Chen, X., Huang, X., Chang, L., Wang, L., \& Li, D. (2010). Aggression, social 553 competence, and academic achievement in Chinese children: a 5-year $554 \quad$ longitudinal study. Development and Psychopathology, 22, 583-92. $555 \quad$ doi:10.1017/S0954579410000295

556 Cohen, J. (1992). A power primer. Psychological Bulletin, 112, 155-159.

557 Davis-Kean, P, E. (2005). The influence of parent education and family 558 income on child achievement: The indirect role of parental expectations 559 and the home environment. Journal of Family Psychology, 12, 294-304. $560 \quad$ http://dx.doi.org/10.1037/0893-3200.19.2.294

561 Deighton, J., et al. (under review). Longitudinal assoications between 562 children's mental health difficulties and their academic perfomance: a 563 study of developmental cascades. Development and Psychopathology.

564 Department for Education. (2013). Children with Special Educational Needs 565 2013: An analysis. London: DfE.

566 Durlak, J., Weissberg, R., Dymicki, A., Taylor, R., \& Schellinger, K. (2011).

567 The impact of enhancing students' social and emotional learning: A meta568 analysis of school-based universal interventions. Child Development, 82, $569 \quad 405-432$. 
Ek, E., Sovio, U., Remes, J., \& Jarvelin, M. (2005). Social predictors of unsuccessful entrance into the labour market-A socialization process perspective. Journal of Vocational Behaviour, 66, 471-486. doi: 10.1016/j.jvb.2004.02.002

Fredrickson, N. L., \& Furnham, A, F. (2004). Peer-assessed behavioural characteristics and sociometric rejection: Differences between pupils who have moderate learning difficulties and their mainstream peers. The British Journal of Educational Psycology, 74, 391-410.

Frostad, P., \& Pijl, S, J. (2007). Does being friendly help in making friends? The relation between the social position and social skills of pupils with special needs in mainstream education. European Journal of Special Needs Education, 22, 15-30.

Gagnon, C., Craig, W.M., Tremblay, R.E., Zhou, R.M., Vitaro, F. (1995). Kindergarten predictors of boys' stable behavior problems at the end of elementary school. Journal of Abnormal Child Psychology, 23,751-66.

Goodman, R. (1997). The Strengths and Difficulties Questionnaire: A research note. Journal of Child Psychology and Psychiatry, 38, 581-586. doi:10.1111/j.1469-7610.1997.tb01545.x

Goodman, R. (2001). Psychometric properties of the strengths and difficulties questionnaire. Journal of the American Academy of Child and Adolescent Psychiatry, 40, 1337-45. doi:10.1097/00004583-200111000-00015 
591 Green, H., McGinnity, A., Meltzer, H., Ford, T., \& Goodman, R. (2005). Mental 592 Health of Children and Young People in Great Britain. London: Office for $593 \quad$ National Statistics.

594 Haapasalo, J., \& Tremblay, R.E. (1994). Physically aggressive boys from 595 ages 6 to 12: family background, parenting behavior, and pre- diction of 596 delinquency. Journal of Consulting and Clinical Psychology, 62, 1044-52.

Hale, D. R., Pataly, P., Fitzgerald-Yau, N., Hargreaves, D. S., Bond, L., Görzig, A.,...Viner, R. M. (2014). School-level variation in health outcomes in adolescence: Analysis of three longitudinal studies in England. Prevention Science, 15, 600-610. doi: 10.1007/s11121-0130414-6.

Hampton, N, Z., \& Mason, E. (2003). Learning Disabilities, Gender, Sources of Efficacy, Self-Efficacy Beliefs, and Academic Achievement in High School Students. Journal of School Psychology, 41, 101-112. doi:10.1016/S0022-4405(03)00028-1

Hox, J., \& Maas, C. (2001). The accuracy of multilevel structural equation modelling with pseudobalanced groups and small samples. Structrual Equation Modelling, 8, 157-174.

Hu, L., \& Bentler, P. (1999). Cutoff criteria for fit indexes in covariance structure analysis: Conventional criteria versus new alternatives. Structural Equation Modelling, 6, 1-55. doi: 10.1080/10705519909540118 
612 Hubbard, R., \& Lindsay, R. M. (2008). Why P values are not a useful measure 613 of evidence in statistical significance testing. Theory \& Psychology, 18, $614 \quad$ 69-88. doi:10.1177/0959354307086923

615 Humphrey, N., \& Ainscow, M. (2006). Transition club: Facilitating learning, participation and psychological adjustment during the transition to secondary school. European Journal of Psychology of Education, 21,

Humphrey, N., Lendrum, A., \& Wigelsworth, M. (2010). Social and Emotional Aspects of Learning ( SEAL ) Programme in Secondary Schools : National Evaluation. London: Department for Children, Schools and Families.

623 Johnston, C., \& Gowers, S. (2005). Routine outcome measurement: A survey 624 of UK child and adolescent mental health services. Child and Adolescent 625 Mental Health, 10, 133-139. doi:10.1111/j.1475-3588.2005.00357.x

626 Kochenderfer, B. J., \& Ladd, G. W. (1996). Peer victimization: Cause or consequence of school maladjustment? Child Development, 67, 13051317.

629 Kaukiainen, A., Salmivalli, C., Lagerspetz, K., Tammient, M., Vauras, M., 630 Mäki, H.,..et al. (2002). Learning difficulties, social intelligence, and self631 concept: Connections to bully-victim problems. Scandinavian Journal of 632 Psychology, 43, 269-278. 
Lerner, R. M., \& Castellino, D. R. (2002). Contemporary developmental theory and adolescence: developmental systems and applied developmental science. Journal of Adolescent Health, 31, 122-135. doi:10.1016/S1054$139 \times(02) 00495-0$

Lewin-Bizan, S., Bowers, E. P., \& Lerner, R. M. (2010). One good thing leads to another: Cascades of positive youth development among American adolescents. Development and Psychopathology, 22, 759-70. doi:10.1017/S0954579410000441

Masten, A. S., \& Cicchetti, D. (2010). Developmental cascades. Development and Psychopathology, 22, 491-5. doi:10.1017/S0954579410000222

Masten, A. S., Roisman, G. I., Long, J. D., Burt, K. B., Obradovic, J., Riley, J. R., ... Tellegen, A. (2005). Developmental cascades: Linking academic achievement and externalizing and internalizing symptoms over 20 years. Developmental Psychology, 41, 733-46. doi:10.1037/00121649.41.5.733

McCarty, C. A, Mason, W. A., Kosterman, R., Hawkins, J. D., Lengua, L. J., \& McCauley, E. (2008). Adolescent school failure predicts later depression among girls. The Journal of Adolescent Health : Official Publication of the Society for Adolescent Medicine, 43, 180-7. doi:10.1016/j.jadohealth.2008.01.023

Moilanen, K. L., Shaw, D. S., \& Maxwell, K. L. (2010). Developmental cascades: Externalizing, internalizing, and academic competence from 

middle childhood to early adolescence. Development and Psychopathology, 22, 635-53. doi:10.1017/S0954579410000337

Monchy, M, D., Pijl, S, J., \& Zandberg, T. (2004). Discrepancies in judging social inclusion and bullying of pupils with behaviour problems. European Journal of Special Needs Education, 19, 317-330.

Petrides, K. V., Furnham, A., \& Mavroveli, S. (2007). Trait emotional intelligence: Moving forward in the field of El. In Matthews, G., Zeidner, M., \& Roberts, R. (Eds.), The science of emotional intelligence: Knowns and unknowns (pp. 151-166). USA: Open University Press.

Qualter, P., Dacre Pool, L., Gardner, K.J., Ashley-Kot, S., Wise, A., \& Wols, A. (2015). The Emotional Self-Efficacy Scale: Adaptation and validation for young adolescents. Journal of Psychoeducational Assessment, 33,:3345. doi: $10.1177 / 0734282914550383$

Qualter, P., Gardner, K.J., Pope, D., Hutchinson, J.M., \& Whiteley, H.E (2012). Ability emotional intelligence, trait emotional intelligence, and academic success in British secondary schools: A 5-year longitudinal study. Learning and Individual Differences, 22, 83-91. doi: 10.1016/j.lindif.2011.11.007

Romano, E., Babchishin, L., Pagani, L. S., \& Kohen, D. (2010). School readiness and later achievement: replication and extension using a nationwide Canadian survey. Developmental Psychology, 46, 995-1007. doi:10.1037/a0018880 
Sklad, M., Diekstra, R., Ritter, M., \& Ben, J. (2012). Effectiveness of school based universal social, emotional, and behavioral programs: Do they enhance students' development in the area of skill, behavior, and.adjustment? Psychology in the Schools, 49, 892 - 909. doi:10.1002/pits

Southampton Psychology Service. (2003). Emotional Literacy: Assessment and Intervention. London: NferNelson.

Tabachnick, B, G., \& Fidell, L, S. (2013). Using Multivariate Statistics. Pearson: USA

Vaillancourt, T., Brittain, H. L., McDougall, P., \& Duku, E. (2013). Longitudinal links between childhood peer victimization, internalizing and externalizing problems, and academic functioning: Developmental cascades. Journal of Abnormal Child Psychology, 41, 1203-1215. doi:10.1007/s10802-013$9781-5$

ValÅs, H. (1999). 2. Students with learning disabilities and low-achieving students: Peer acceptance, loneliness, self-esteem, and depression. Social Psychology of Education, 3, 173-192.

Van Cleave, J., \& Davis, M, M. (2006). Bullying and peer victimization among children with special health care needs. Pediatrics, 118, 1212-1219.

Vidal Rodeiro, C.L., Bell, J.F., \& Emery, J.L. (2009). Can emotional and social abilities predict differences in attainment at secondary school? Research Matters, 7, 17-22. 
699 Wigelsworth, M., Lendrum, A., Oldfield, J., Scott, A., Ten-Bokkel, I., Tate, K., \& Emery, C. (in press). The impact of trial stage, developer involvement and international transferability on universal social and emotional learning programme outcomes: A meta-analysis. Cambridge Journal of Education.

704 Footnote

$705{ }^{1}$ The Key Stages in the English education system are ages 5-7 (Key Stage 1), 7-11 (Key 706 Stage 2), 11-14 (Key Stage 3), and 14-16 (Key Stage 4). 